\title{
Dual Axis Solar Tracking System with LDR
}

\author{
B.Mohan ${ }^{1}$, M.V.Ramesh ${ }^{2}$, Melimi Ravi Kumar ${ }^{3}$, T.SrinivasaRao ${ }^{4}$, P. Muthukumar ${ }^{5}$ \\ ${ }^{1}$ Assistant Professor, mohan.victory1@gmail.com \\ ${ }^{2}$ Associate Professor, vrmaddukuri@gmail.com \\ ${ }^{3}$ Assistant Professor, ravikumar.melimi@gmail.com \\ ${ }^{4}$ Assistant Professor, srinuthumati@gmail.com \\ ${ }^{5}$ Associate Professor, muthukumarvlsi@gmail.com \\ PVP Siddhartha Institute of Technology, Vijayawada, Andhra Pradesh, India
}

\begin{abstract}
Main problem now a day is ozone layer depletion is a consequence of using conventional energy sources in the world.In the coming years the development of PV systems is the best choice for energy generation. To abstract the energy effectively from the solar, the PV system is to be inclined depending on the sun angle. The angle of sun depends on day time and season. The structure of the PV system is to be designed so that it has two dimensional movements. The angle of the sun is sensed using LDR sensor by sending the info flag to the controller. The controller sends the signal to the motor to change the direction of the structure. The proposed work deals with the design of the system for the dual axis rotation depending on the sun inclination. The use of this solar tracking system is beneficial for more energy generation and cost effective.
\end{abstract}

Key words: Arduino Microcontroller, Solar Tracker, LCD, Servo motor, LDR.

\section{INTRODUCTION}

The solar energy is a renewable energy source which is having more possibility for direct conversion into electrical energy. Solar energy conversion is silent, less maintenance cost, clean, small ecological impact and reliable [1]. The importance of PV system is increasing exponentially. In the coming decades the projection of market growth is strong [2]. Huge demand on the clean and reliable energy has given scope on research for solar energy generation. The research studies focus on implementation of more efficient and reliable solar PV system [6]. The solar energy collection can be better utilized by implementing solar tracking system. Controller plays an important role in the dual axis tracking mechanism [4].

Main objective of paper is to implement solar tracking system, specifically dual axis system to harness solar energy by following the path of the source of radiation. According to the construction, solar tracking system can rotate in both axes [5]. The prime interest lies in the validating the statement that dual axis tracker is much efficient in harnessing solar energy that of a standard solar panel [7].

The proposed system involves the usage of solar panel to harness the energy from the sun (or other illuminating sources). Utilizing the servomotors, the panel is rotated towards the direction with the maximum amount of radiation [8]. The servomotors receive commands from the ATMEGA328P microcontroller based on the values given by the LDR`s. The entire system is supplied power by the supply unit that supplies voltages at $5 \mathrm{~V}$ and $12 \mathrm{~V}$ respectively. The information from the LDR`s is displayed on the LCD [9] [10].

\section{BASIC MODEL OF THE SYSTEM AND DESCRIPTION}

\subsection{Designed Circuit Diagram}

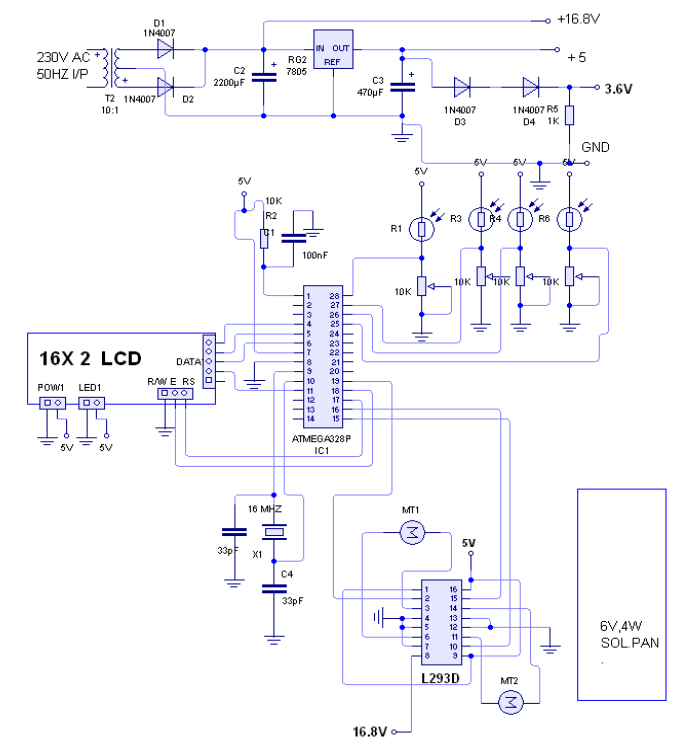

Figure 1: Designed Circuit diagram of proposed system

\subsection{Block Diagram of Power Conversion Stages}

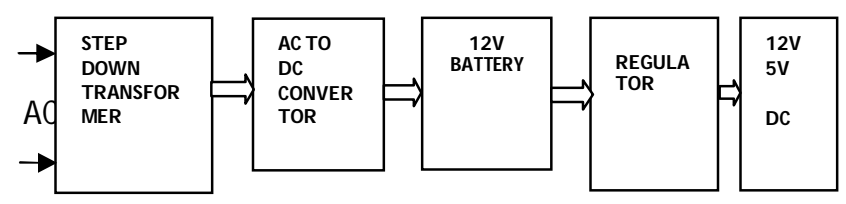

Figure 2: Block diagram of power conversion for the Designed system 


\subsection{Block Diagram of Arduino Interfacing with Other Hardware Components}

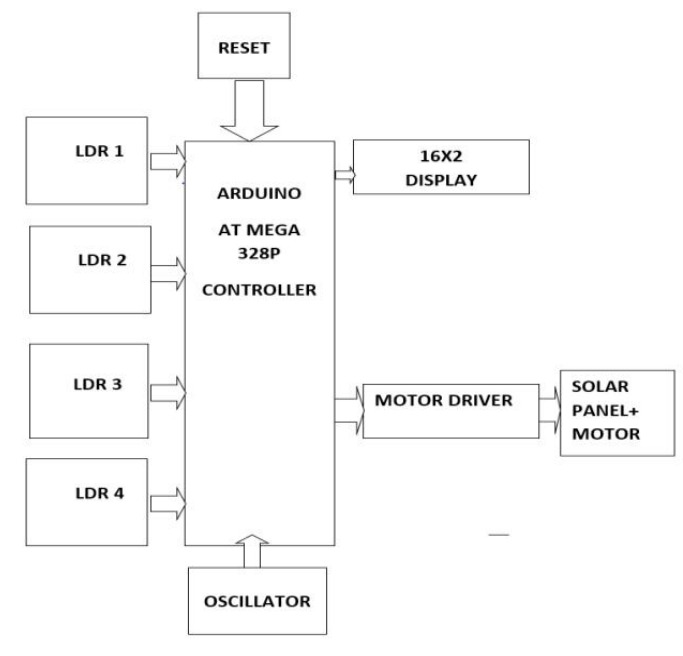

Figure 3: Block diagram of Arduino interfacing with other hardware components

\subsection{Components used in the model}

Microcontroller is the main part of proposed system. It constantly monitors digitalized parameters of different LDR's and verifies them with the threshold values and checks if the values reach the threshold. In such conditions, it activates the motors to perform the operations.

LCD is utilized to indicate present status of the parameter values. The information display can be interfaced to operation of the system with respective changes in irradiation.

The working principle of LDR is photo conductivity [3]. Photo conductivity means electrical conduction takes place because of absorption of electromagnetic radiation. Conductivity of material decreases as it absorbs light. When LDR absorbs light the electrons in valence band are eager to move to conduction band. This is possible only when photons of the incident light have more energy than the band gap of material. The number of charge carriers depends on whether intrinsic type or extrinsic type semiconductor is used in LDR.As the more current starts flowing, resistance of material decreases.

Solar panel is prepared with a number of small photovoltaic cell. The panel absorbs the radiation from the surrounding and generates electricity which can be utilized for various purposes.

Solar tracker orients payload towards Sun. Payload may be a solar panel or parabolic or dish collectors or Fresnel lenses or heliostat mirrors. For flat panel PV systems, tracker reduces the incidence angle between sun irradiation and PV array. The light dependent components used in the tracking mechanism are to be oriented properly to trap the maximum solar irradiation and convert it to equivalent other form of energy.
Dual axis tracker consists of two degrees of choice to operate as axes of rotation. Axis that fixed to ground is taken as primary axis and referred to primary axis is taken as secondary axis. There are two methods used for implementation of dual axis trackers. They are tip-tilt dual axis trackers and azimuth-altitude dual axis trackers. When modelling performance is taken, orientation of the module plays vital role for the tracker axis. This tracker has modules oriented in shunt to the secondary axis. This tracker permits the panel structure to follow the Sun in both vertical and horizontal directions.

Servomotor is a main moving device of the entire system. As per the input given by the microcontroller, the servomotor rotates as per the direction determined through comparison of the values by the LDR`s.

\section{FLOWCHART}

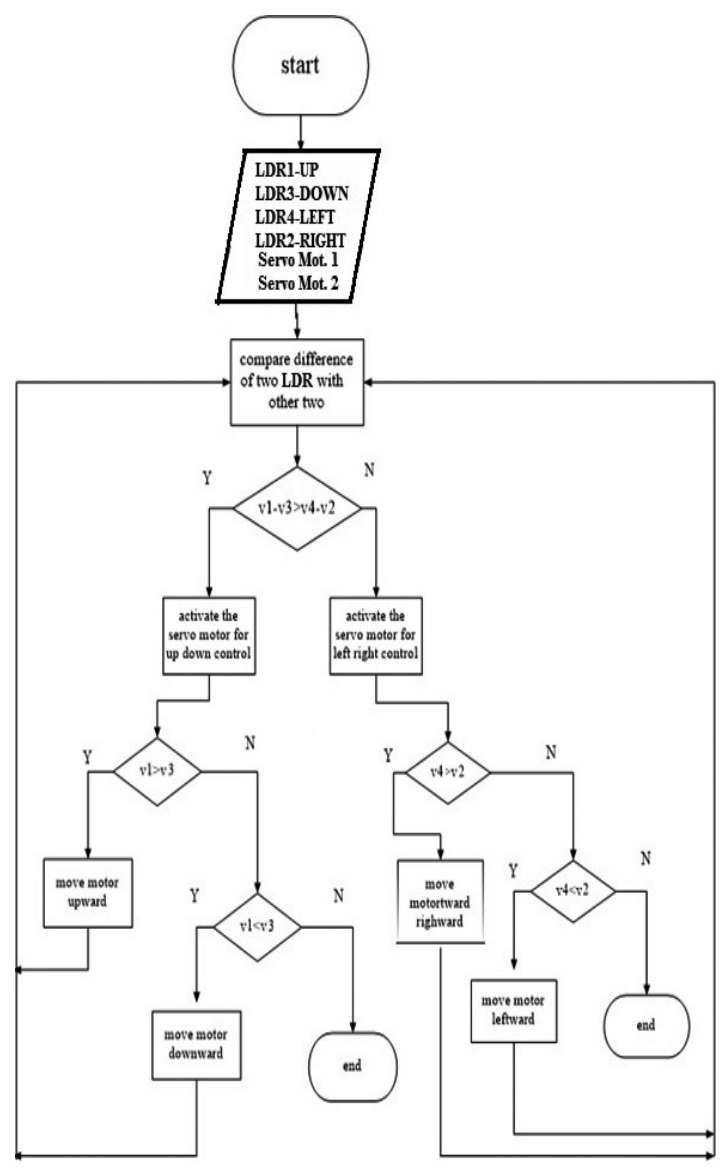

Figure 4: Flow chart for the proposed system

\section{RESULTS AND DISCUSSIONS}

The below figure shows the overview of the implemented hardware of the proposed system.

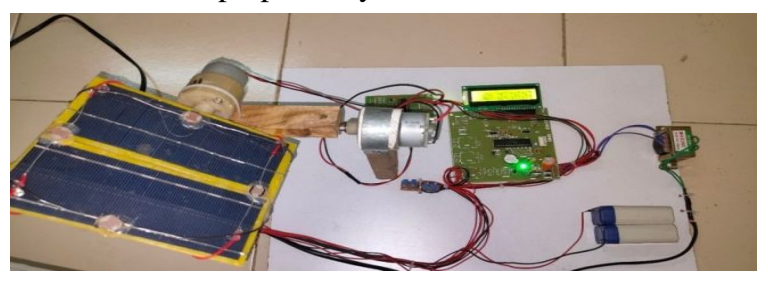

Figure 5: Implemented Hardware of the proposed system 
The resistance developed varies according to the concentration of the radiation on the LDR. These values can be observed in the LCD present in the system. Utilizing the code available in the Arduino, the commands are sent to the servomotor which rotates thereafter. The values obtained during a particular session of the process can be displayed on LCD as shown below figure.

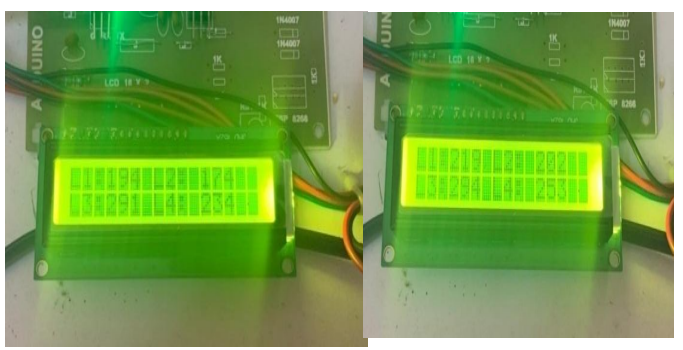

Figure 6: LCD Display of resistance value of LDR

Table: Comparison of power delivered by fixed panel and dual axis tracking solar panel

\begin{tabular}{|c|c|c|c|c|c|}
\hline \multicolumn{3}{|c|}{ Fixed solar panel } & \multicolumn{3}{c|}{$\begin{array}{c}\text { Solar panel with } \\
\text { dual axis tracking }\end{array}$} \\
\hline $\begin{array}{c}\text { Volta } \\
\text { ge } \\
\text { (V) }\end{array}$ & $\begin{array}{c}\text { Curre } \\
\text { nt } \\
(\mathrm{mA})\end{array}$ & $\begin{array}{c}\text { Power } \\
(\mathrm{mW})\end{array}$ & $\begin{array}{c}\text { Voltage } \\
\text { (V) }\end{array}$ & $\begin{array}{c}\text { Curren } \\
\mathrm{t}(\mathrm{mA})\end{array}$ & $\begin{array}{c}\text { Power } \\
(\mathrm{mW})\end{array}$ \\
\hline 8.6 & 1.25 & 10.75 & 10.42 & 3.00 & 31.26 \\
\hline 9.7 & 1.82 & 17.65 & 10.51 & 3.23 & 33.94 \\
\hline 9.9 & 2.22 & 21.97 & 10.60 & 3.20 & 33.92 \\
\hline 10.3 & 2.56 & 26.36 & 10.80 & 3.35 & 36.18 \\
\hline 10.5 & 2.97 & 31.18 & 10.73 & 3.41 & 36.58 \\
\hline 9.7 & 2.71 & 26.28 & 10.40 & 3.29 & 34.21 \\
\hline $\begin{array}{c}\text { Average } \\
\text { power in } \\
\text { mW }\end{array}$ & 22.36 & & 34.34 & \\
\hline
\end{tabular}

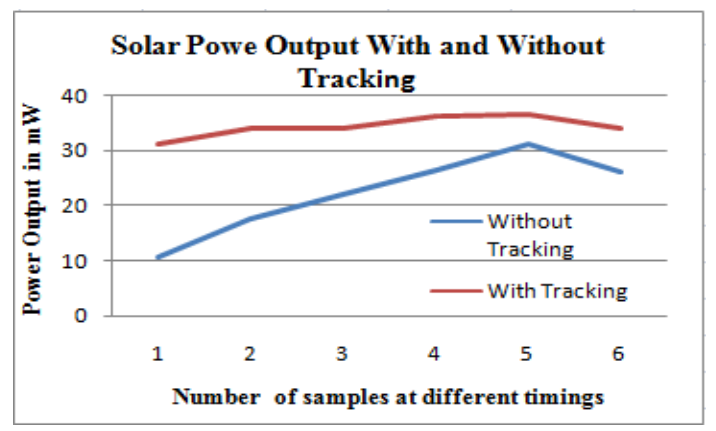

Figure 7: Solar power output with and without tracking

The comparison of power delivered by using fixed position panel and dual axis tracking solar panel is presented in the table, from the above table; the prime aim of the model is validated. The average amount of power extracted using fixed solar panel is less than that of the dual axis tracking solar panel.

Wattage from the solar panel is obtained by the multiplication of the voltage in volts and the current in mill amperes. Calculations prove that the dual axis solar panel has around

$35 \%-50 \%$ more output when compared to the fixed solar panel.

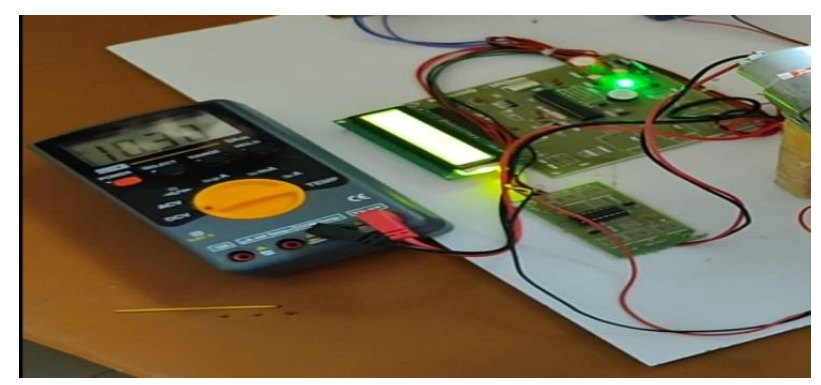

Figure 8: Voltage measured from dual axis solar panel

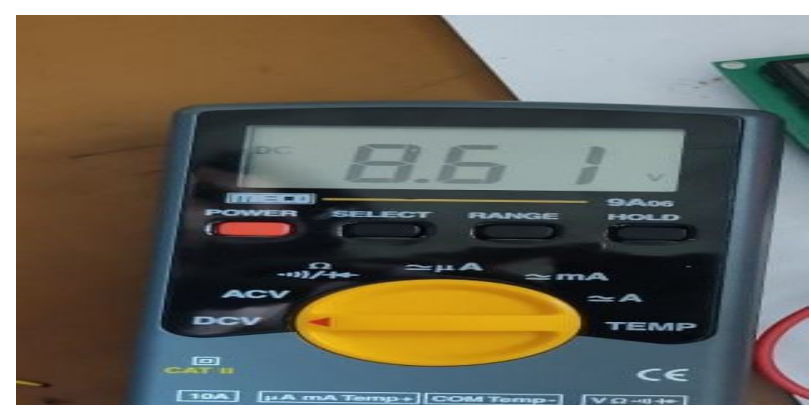

Figure 9: Voltage measured from fixed axis solar panel

From the above measurements we can observe that the dual axis solar system is producing more voltage compared to the fixed solar system.

\section{CONCLUSION}

In this model dual axis solar tracking system with LDR was designed with the help of microcontroller. The implemented sun tracking solar PV system is a viable means to maximize energy collected from solar rays. LDR sensor is utilized for tracking the sun radiation. The controller used in this model is designed with minimum components. The servomotor is used for tracking the sun accurately by keeping track of previous position of PV array and the current solar inclination. More solar energy is collected by using automatic solar tracker. It is observed by using dual axis tracking the percentage increase in energy generated is more during morning and evening times. The percentage improvement in energy is less during afternoon time. The overall day average improvement in the energy is about 35 to 50 percentage.

\section{REFERENCES}

1. Liwei Du, Xun Ma, Zuming Liu, Benqian Qin, Xiaojuan Zhong, Taixiang Zhao "Comparison of Various Tracking Modes on Improvement of PV Power Generation System" 2019 IEEE 3rd International Electrical and Energy Conference (CIEEC) 978-1-7281-1675-4/20. 
2. Tung-Sheng Zhan, Whei-Min Lin, Ming-Huang Tsai Guo-Shiang Wang "Design and Implementation of the Dual-axis Solar Tracking System " 2013 IEEE $3^{7 \text { th }}$ Annual Computer Software and Applications Conference.

3. Divya Mereddy, Vijaya Rama Raju.V, Tharun Sadula "Smart Dual Axes Solar Tracking" 2015 International Conference on Energy Systems and Applications (ICESA 2015) Dr. D. Y. Patil Institute of Engineering and Technology, Pune, India 30 Oct - 01 Nov, 2015. https://doi.org/10.1109/ICESA.2015.7503373

4. Mohammed Saifuddin Munna, Mohammed Saifuddin Munna, Kazi Mustafizur Rahman, Md. Ashiqul Hoque "Design, Implementation and Performance Analysis of a Dual-Axis Autonomous Solar Tracker" 978-15090-0169-9/15/\$31.00 (C2015 IEEE.

5. Mr. S. G. Mane, Dr. Iranna Korachagaon, Mr. M. R. Hans "Simulation of Dual Axis Solar Tracking System" 2018 International Conference on Information, Communication, Engineering and Technology (ICICET) Zeal College of Engineering and Research, Narhe, Pune, India. Aug 29-31, 2018.

6. Smirnov A.A, Malugin S.A., Bakanov A.V. “ Designing Integrated PV Facility with Dual-Axis Solar Tracking System Mounted on the South Building Face" 2017 International Conference on Industrial Engineering, Applications and Manufacturing (ICIEAM).

7. Jamilu Ya'u Muhammad, Mohammed Tajudeen Jimoh, Ibrahim Baba Kyari, Mohammed Abdullahi Gele, Ibrahim Musa, "A Review on Solar Tracking System: A Technique of Solar Power Output Enhancement", Engineering Science. Vol. 4, No. 1, 2019, pp. 1-11. doi: 10.11648/j.es.20190401.11.

8. Sunil Kumar Jilledi, Daniel Tesfazgi, Filmon Foto, Mahmud Ali, Abduselam Atta, Alexander Yemane, "Design and Simulation of Dual Axis Solar Tracker for Optimum Solar Energy Absorption", International Journal of Sensors and Sensor Networks. Vol. 7, No. 3, 2019, pp. 34-43. doi: 10.11648/j.ijssn.20190703.11.

9. Eunsung Oh" Rolling Based Energy Storage System Operation Strategies Considering wind power forecast Uncertainty", International journal of Emerging Trends in Engineering research (IJETER), volume 7, No.11 November 2019, ISSN 2347-3983, pages $708-714$. https://doi.org/10.30534/ijeter/2019/497112019

10. Harshitha Surana, Shilpha B Harvesh" Clock Gating Using Energy Efficient Double Edge Triggered Flip Flop For Streaming Applications", International journal of Emerging Trends in Engineering research (IJETER), volume 6, No.6 June 2018, ISSN 2347-3983, pages 33-39.

https://doi.org/10.30534/ijeter/2018/01662018 